\title{
Morphology and formation mechanism of sand shadow dunes on the Qinghai-Tibet Plateau
}

\author{
JianHua XIAO ${ }^{1,2}$, JianJun $\mathrm{QU}^{1,2,3^{*}}$, ZhengYi YAO ${ }^{1}$, YingJun PANG ${ }^{1,2}, \mathrm{KeCun} \mathrm{ZHANG}^{1,2}$ \\ ${ }^{1}$ Key Laboratory of Desert and Desertification, Cold and Arid Regions Environmental and Engineering Research Institute, \\ Chinese Academy of Sciences, Lanzhou 730000, China; \\ ${ }^{2}$ Dunhuang Gobi and Desert Ecology and Environment Research Station, Cold and Arid Regions Environmental and Engineering \\ Research Institute, Chinese Academy of Sciences, Dunhuang 736200, China; \\ ${ }^{3}$ Gansu Center for Sand Hazard Reduction Engineering and Technology, Lanzhou 730000, China
}

\begin{abstract}
The formation and development of dunes depend on wind-blown sand movement which is affected by the characteristics of sand material, topography, wind regimes and other factors. In this paper, we investigated two sand shadow dune groups in Shigatse and Za'gya Zangbo of Tibet and an individual dune in Da Qaidam of Qinghai, and analyzed their topographies and morphologies, and the physical characteristics of the sand, wind regime and sand transport. Formed under harsh conditions behind hills, these mature sand shadow dunes are hundreds of meters long, have significant ridges and crescent dunes downwind, and have a hill pass on one or both sides. Wind tunnel experiments revealed that the hill gap and wind velocity are important factors in the formation of these dunes. Sand shadow dunes formed only when the gap spacing is two-thirds of the hill height. When wind velocities are 20 $\mathrm{m} / \mathrm{s}$, the sand body is divided into two parts. The hill pass allows the transport of sand by wind, creating a "narrow-pipe effect", which causes the transported material to gradually accumulate in the center of the shadow zone. We observed that the following are needed for sand shadow dunes to form: (1) strong winds, sufficient sand, suitable obstacles and a dry climate; (2) one or both sides of the obstacle forming the shadow zone must have a hill pass; and (3) the windward side of the obstacle must have a wide, flat area, providing adequate spacing for wind flow and transport of material and the leeward side must have a sufficiently broad, flat area to allow the release of the transported material. Research results on these newly discovered dunes on the Qinghai-Tibet Plateau could contribute to the understanding of dune geomorphology.
\end{abstract}

Keywords: sand shadow dune; morphology; aeolian landform; wind tunnel; Qinghai-Tibet Plateau

Citation: JianHua XIAO, JianJun QU, ZhengYi YAO, YingJun PANG, KeCun ZHANG. 2015. Morphology and formation mechanism of sand shadow dunes on the Qinghai-Tibet Plateau. Journal of Arid Land, 7(1): 10-26. doi: 10.1007/s40333-014-0074-9

Aeolian geomorphology is the product of the processes of wind erosion and deposition on the earth surface. Thus, the formation and development of aeolian deposition landforms (dunes) depend on wind-blown sand movement ( $\mathrm{Wu}, 2003)$. Wind-blown sand movement is affected by the characteristics of the sand material, topography, wind regime and other factors. Researches into the history of aeolian geomorphology, both in China and internationally, have greatly enhanced the knowledge of sand dune morphology, formation and development conditions, dynamic processes of formation and evolution and regional differentiation regularity that constitute the main body of the theoretical system of aeolian geomorphology (Lancaster, 1995; Li and Ni, 2000; Livingstone et al., 2007). Traditional dune geomorphology researches tend to focus on the formation and evolution of dunes that are in area unaffected by complex terrain (Pye and Tsoar, 1990; Tsoar and Blumberg, 2002); however, sand dunes forming in complex terrain are ubiquitous in nature. Complex terrain includes characteristics such as cliffs, mountains, buildings, embankments,

"Corresponding author: JianJun QU (E-mail: qujianj@lzb.ac.cn) 
cuttings and fences. Complex topography can decelerate, accelerate and otherwise control the direction of the air or wind-blown sand flow, particularly on the leeward side of structures in the flow. These changes in wind-blown sand movement lead to different erosion and deposition near the complex terrain, forming a variety of sand dunes, including echo dunes, climbing dunes, cliff-top dunes, falling dunes and sand shadow dunes (Evans, 1962; Cooke and Warren, 1973; Tsoar, 1983; Elbelrhiti et al., 2005; Elbelrhiti, 2012).

Sand shadow dunes have been observed since the 1940s. Bagnold (1941), the pioneer of blown-sand research, described sand shadow dunes as the material deposited when the wind velocity is checked locally by an obstacle in its path, accumulating in the shelter of, and immediately behind, the obstacle. Some researchers have called this a shadow dune or a wake dune (Wu, 2003). Sand shadow dunes have also been described by Pidgeon (1940), Salisbury (1952) and Cooper (1958) in connection with coastal dunes behind vegetation. Describing the pyramidal, lee-trending form of the dunes, they concluded that the dunes formed with various plant species. Bressolier and Thomas (1977) analyzed the relationship between plant density and height and the wind velocity profile. Hesp (1981) researched shadow dunes formed by the flow around a plant, and found that the separated flow over the plant appeared to have little effect in forming the dune compared with the horizontal flow around the plant near the bed. Gunatilaka and Mwango (1989) researched the internal structure of shadow dunes. Luo et al. (2012a, b, 2014) made a lot of researches on the three-dimensional airflow patterns and near-wake flow patterns in wind tunnel, and they found that the larger the gap spacing between obstacles, the more quickly wind velocity recovered downwind of the gap.

However, sand shadow dunes forming by largescale obstacles (such as hills) have been reported rarely, and the morphological characteristics and formation conditions of sand shadow dunes remain unclear. The conditions necessary for the formation of sand shadow dunes are more complex than those needed for echo dunes, climbing dunes and cliff-top dunes, and the distribution of sand shadow dunes is relatively scarce.

In 2012, we conducted a field survey of aeolian landforms on the Qinghai-Tibet Plateau and were the first to discover many sand shadow dunes in Shigatse and Za'gya Zangbo of Tibet and Da Qaidam of Qinghai. These dunes were hundreds of meters long and had been formed because of the presence of local hills (Fig. 1). We investigated three sand shadow dune areas and analyzed their topographies and morphologies, and the physical characteristics of the sand, wind regime and sand transport. Wind tunnel experiments were performed to simulate their formation processes. On the basis of the preliminary results, we discussed the formation mechanism of sand shadow dunes and compared the differences in morphological characteristics and formation mechanisms with those of typical sand shadow dunes, climbing dunes, linear dunes and barchan chains.

\section{Study areas and methods}

\subsection{Study areas}

This study was conducted on two sand shadow dune groups in Shigatse and Za'gya Zangbo of Tibet and one individual dune in Da Qaidam of Qinghai (Fig. 2). The Shigatse sand shadow dune lies near the Nianchu River valley in Gadong, and it is $31 \mathrm{~km}$ from Shigatse in Tibet $\left(29^{\circ} 13^{\prime} 19^{\prime \prime}-29^{\circ} 15^{\prime} 05^{\prime \prime} \mathrm{N}\right.$, $89^{\circ} 11^{\prime} 04^{\prime \prime}-89^{\circ} 12^{\prime} 38^{\prime \prime} \mathrm{E} ; 4,000 \mathrm{~m}$ asl). The area is dominated by gobi, farmland and valleys and is surrounded by hills. The Za'gya Zangbo sand shadow dune lies in Amdo county, Nagchu Prefecture, Tibet (32³0'48"-32 $35^{\circ} 42^{\prime \prime} \mathrm{N}, 91^{\circ} 23^{\prime} 40^{\prime \prime}-91^{\circ} 30^{\prime} 46^{\prime \prime} \mathrm{E}$; 4,850 $\mathrm{m}$ asl). The area is located south of the Tanggula Mountains $(>6,000 \mathrm{~m}$ asl), which constitute the highest mountain range in central Tibet. This area is uninhabited and consists mainly of large river systems that are part of the Za'gya Zangbo River. The land surface of the area is covered mainly by sparse tundra vegetation, desert and numerous dwarf stone mountains formed from tectonic movements and weathering. The Da Qaidam sand shadow dune lies in the north-central Haixi prefecture, Qinghai (37 $45^{\prime} 24^{\prime \prime} \mathrm{N}, 95^{\circ} 14^{\prime} 37^{\prime \prime} \mathrm{E}$; 3,300 $\mathrm{m}$ asl). The area is located in the Qaidam Basin and includes a large salt lake and a desert. It borders the Qilian Mountains to the north.

The Shigatse, Za'gya Zangbo and Da Qaidam sand shadow dunes are located in the north, middle and 




Fig. 1 Photograph of sand shadow dunes in Za'gya Zangbo: (a) and (b) are Dune 1; (a) is taken from a hill peak; (b) is taken from a distance; (c) is Dune 3; (d) is Dune 2.



Fig. 2 Location of the study areas

south of the Qinghai-Tibet Plateau, respectively, and their elevations are 3,300, 4,000 and 4,850 $\mathrm{m}$ respectively. They have a spatial pattern that is typical of the Qinghai-Tibet Plateau, comprising individual dunes and dune groups, and also containing small and large dunes, which can better represent the sand 
shadow dunes on the Qinghai-Tibet Plateau.

\subsection{Data and methods}

Zhu et al. (1981), Tsoar (1983) and Tang et al. (2011) studied the morphologic characteristics of different types of dunes (e.g. crescent dunes and linear dunes) by using a variety of methods and measured parameters including slope, length, height and direction. As the development processes of sand shadow dunes are related closely to obstacles and geomorphological conditions, we used remote sensing images to identify the dunes and total station instrument measurement techniques to determine the sand shadow dune length, area, strike and geomorphological parameters. We used digital elevation model (DEM) data to analyze the morphology and topography of the sand shadow dunes. We also collected surface sediment samples (0-1 cm depth) and analyzed particle sizes. From three meteorological stations (Shigatse, Amdo and Da Qaidam), either in or near the study areas, we collected wind data that were recorded by China National Meteorological Information Center. Wind data included daily maximum wind speed and direction.

All surface sediments were analyzed at Ministry of Education Key Laboratory of Western Environment, Lanzhou University by using a particle size analyzer (Mastersizer 2000, Malvern, UK). The data were further analyzed by using a graphical method proposed by Folk and Ward (Zhao, 1991) to calculate particle size parameters. DEM data were taken from the US National Aeronautics and Space Administration's ASTER GDEM V2 with 30-m resolution.

In this study, we developed a series of georeferenced data basing on the accurate interpretation of remote sensing images, which we scanned and then georeferenced by using GIS software (ArcGIS version 9.2). We digitized the sand shadow dune boundaries and ridges which were clearly defined in the remote sensing images. By using the GIS software, we created continuous polygons and polylines to represent the areas and ridges of the sand shadow dunes from the georeferenced remote sensing images, and then digitized these polygons and polylines. We maintained methodological consistency by having a single operator perform all polygon and polyline delineations.

The amount of sand transported is one of the imp- ortant indices reflecting the regional intensity and direction of sand transport. To measure the amount of sand transported, an eight-directional sand trap was placed on the desert around the Za'gya Zangbo sand shadow dunes. The unidirectional mouth of the sand trap is $1.5 \mathrm{~cm}$ wide and $1.0 \mathrm{~m}$ high (Fig. 1b). Sand from a $1-\mathrm{m}$ height lamella in each direction was segregated and stored in different sections of a large drum, about $1.0 \mathrm{~m}$ in diameter, which was buried beneath the surface. The amount of sand transported was observed from October 2012 to September 2013.

The wind tunnel experiments were conducted in a blowing sand wind tunnel at the Key Laboratory of Desert and Desertification of Chinese Academy of Sciences. The wind tunnel is used primarily to simulate blowing sand and surface flow, as was the case in this experiment. The blow-type non-circulating wind tunnel has a total length of $37.78 \mathrm{~m}$ with a test section of $16.23 \mathrm{~m}$ long. The cross-sectional area of the test section is $0.6 \mathrm{~m} \times 1 \mathrm{~m}$. The free-stream wind velocity in the wind tunnel ranges from $1-40 \mathrm{~m} / \mathrm{s}$ and the wind velocity is measured by a Pitot tube connected to a pressure sensor. The model hill, which was made of red mud with a base diameter and height of 15 and 9 $\mathrm{cm}$, respectively, was placed in the test section of the wind tunnel, as shown in Fig. 3, and the sand was planted upwind of the model hill.

\section{Results}

\subsection{Landform characteristics}

The Shigatse sand shadow dunes are surrounded by mountains on three sides and by valley terrain on one side (Fig. 4a). The 217-km Nianchu River, which is the largest tributary of the middle reaches of the Yarlung Tsangpo River, flows from east to west through the area. The Nianchu valley is a well-developed fertile agricultural area known as the "Granary of Tibet". Although the river provides an abundant source of water for farmland, the area is mountainous and prone to flash floods that transport large amounts of sediment and alluvial material from the mountains into the valley. As shown in Fig. 4a, the sand shadow dunes are located in a broad valley on open ground, and there are a large farmland and villages in the windward direction. The river hooks around to the 




Fig. 3 Schematic of wind tunnel experiment set-up



Fig. 4 Landforms in the Shigatse sand shadow dune area: (a) from Bing Map, (b) from Google Maps (number 1-9 mark the position of 9 sand shadow dunes, respectively)

south, and the valley widens to become the open ground.

The Za'gya Zangbo sand shadow dunes lie in a relatively flat area bordered by high mountains to both the north and south (Fig. 5). A large river originates in the mountains and forms a confluence with the Za'gya Zangbo River. The sand shadow dunes are located within one of the largest river valleys in the area.

The Da Qaidam sand shadow dune is located just behind a small hill (Fig. 6). The area between the small hill and the large hill to the south forms a hill pass. To the west is the Qaidam Desert, which is a large area of desert sand material and salt lakes.

\subsection{Sand shadow dune morphology}

The Shigatse sand shadow dune area has nine typical sand shadow dunes distributed downwind of seven mountains (Fig. 4b). Many small shield dunes are found upwind. Dune 9, which is the furthest upwind, is the smallest sand shadow dune and it is closest to the shield dunes. Its morphological characteristics are not obvious. As shown in Fig. 7, the morphological characteristics of the sand shadow dunes, including long sand ridges, become more apparent downwind. Dune 1 is the longest and most typical sand shadow dune with sand ridges up to $579.1 \mathrm{~m}$ long. From the hillside, the linear sand shadow dune extends to the 




$91^{\circ} 20^{\prime} \mathrm{E}$

$91^{\circ} 30^{\prime} \mathrm{E}$

Fig. 5 Topography of the Za'gya Zangbo sand shadow dunes

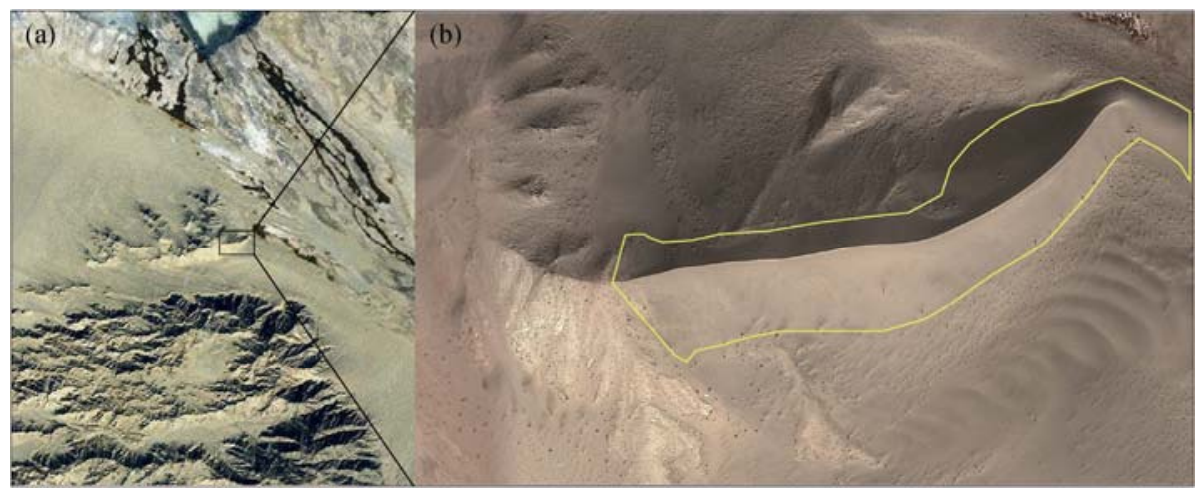

Fig. 6 Landforms in the Da Qaidam sand shadow dune study area: (a) from Bing Map, (b) from Google Maps

endpoint, becomes disconnected, and turns into a series of crescent dunes. Because of both the complex mountain terrain of the mountains and the effects of airflow, some dunes are shorter and some have become integrated with other nearby dunes.

The Za'gya Zangbo sand shadow dunes contain nine typical dunes that differ morphologically from the Shigatse sand shadow dunes (Fig. 8). Most of the
Za'gya Zangbo dunes are formed on the slope downwind of the mountains (Fig. 5), whereas the Shigatse dunes are formed on flat land. As shown in Fig. 8, Za'gya Zangbo has a distinct triangular-shaped dune, which connects to a linear dune. In contrast, the Shigatse dunes are not distinctly triangular-shaped. Dunes 6 and 7 have not formed tall sand bodies, but are dispersed sand dunes (Fig. 8f). Dune 8 is a crescent 


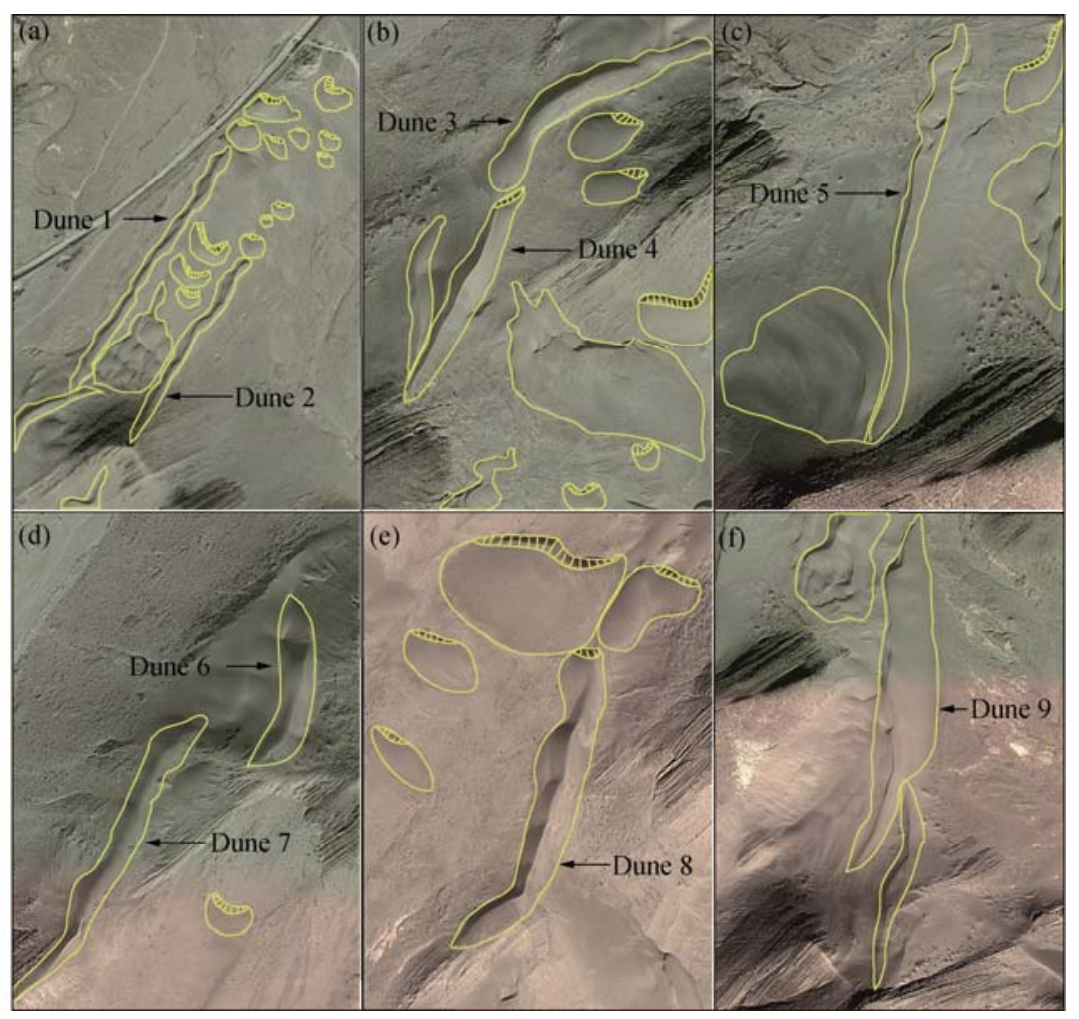

Fig. 7 Photographs of the Shigatse sand shadow dunes: (a) Dune 1 and Dune 2, (b) Dune 3 and Dune 4, (c) Dune 5, (d) Dune 6 and Dune 7, (e) Dune 8, (f) Dune 9 from Google Maps

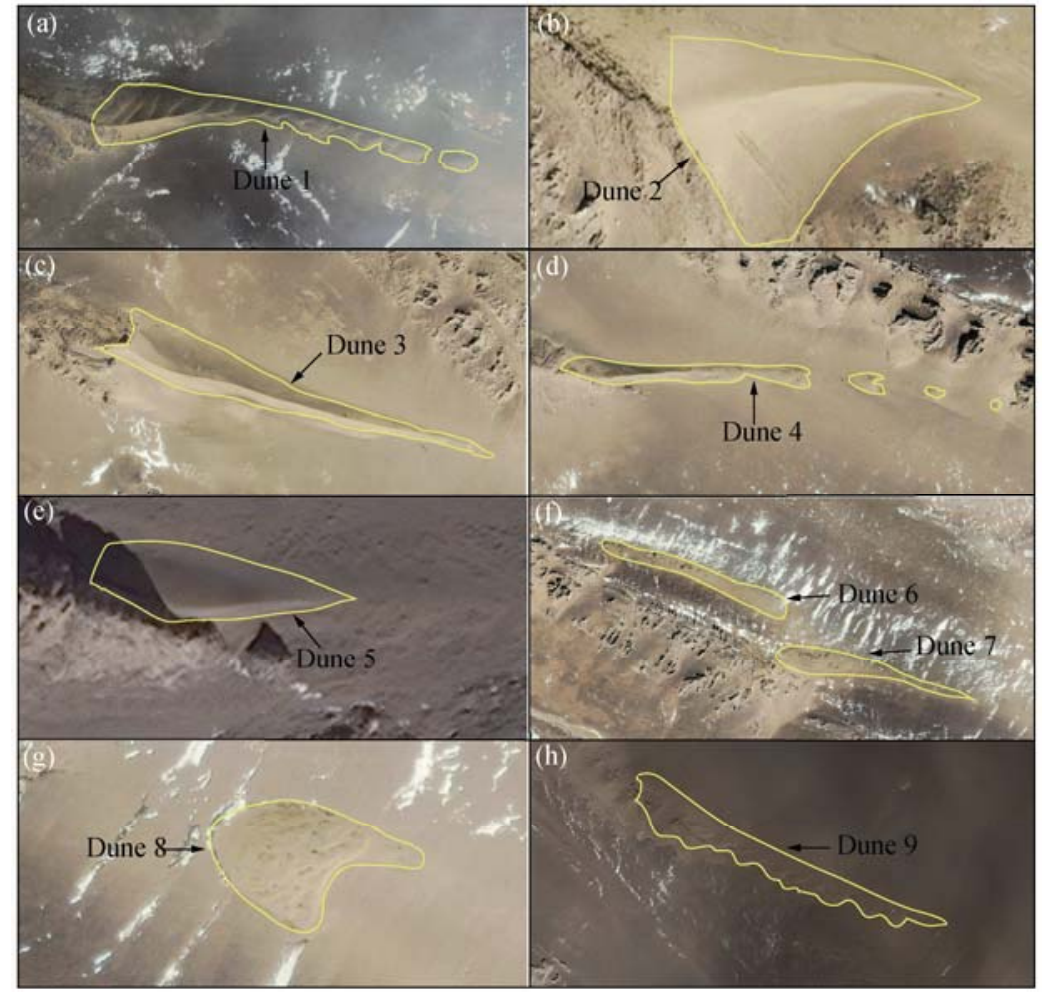

Fig. 8 Photographs of the Za'gya Zangbo sand shadow dunes: (a) Dune 1, (b) Dune 2, (c) Dune 3, (d) Dune 4, (e) Dune 5, (f) Dune 6 and Dune 7, (g) Dune 8, (h) Dune 9 from Google Maps 
dune formed at the end of dune 7 on the hillside (Fig. $8 \mathrm{~g})$. The rest of the Za'gya Zangbo sand shadow dunes have tall sand bodies with sand ridgelines. From dunes 1 and 4 (Figs. 8a and d), we note that there are some crescent dunes at the end of the linear dunes, which are similar to barchan chains or seif dunes in appearance (Wang et al., 2004). One wing of the crescent-shaped dune extends forward and the other wing is shorter and smaller, forming a hook-shaped dune similar to that of a barchan chains.

The morphological characteristics of the Da Qaidam and Za'gya Zangbo sand shadow dunes are similar (Figs. 6b and 8c).

We used remote sensing images and field experimental data, obtained from the total station instrument (Fig. 9), to measure the sand ridge length, dune area and sand ridgeline strike (Table 1). The average lengths of the sand ridges on the Shigatse, Za'gya Zangbo and Da Qindam sand shadow dunes are 373.0, 371.7 and $638.6 \mathrm{~m}$, respectively. We found that the Shigatse sand shadow dunes have slightly longer sand ridges and are larger than the Za'gya Zangbo sand shadow dunes. The strike on the ridges goes clockwise from $0^{\circ}, 90^{\circ}, 180^{\circ}$ and $270^{\circ}$ (i.e. north, east, south and west, respectively).

\subsection{Sediment grain size characteristics of sand shadow dune surfaces}

Grain size characteristics reflect the processes involved in dune formation (Bagnold, 1941). We collected surface sediment samples $(0-1 \mathrm{~cm}$ depth $)$ from five sites and analyzed the grain sizes. As shown in Fig. 6,

(a)

Dune 1 in Za'gya Zangbo
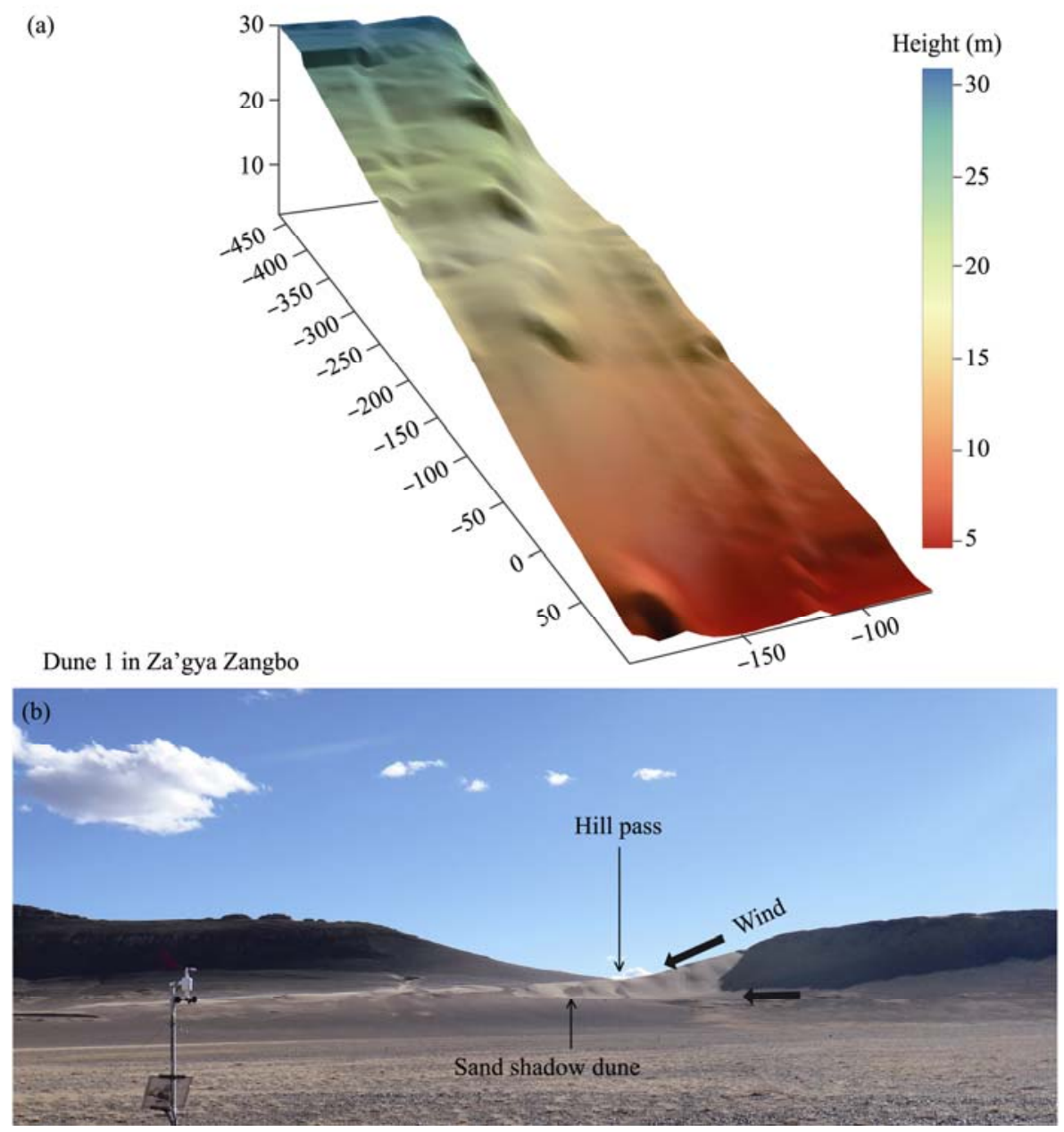

Fig. 9 Topography of dune 1 in the Za'gya Zangbo sand shadow dunes: (a) three-dimensional diagram by total station instrument, (b) photography of area 
Table 1 Parameters used to analyze sand shadow dunes

\begin{tabular}{|c|c|c|c|c|}
\hline Site & Dune No. & Length (m) & Area $\left(\mathrm{m}^{2}\right)$ & Strike $\left({ }^{\circ}\right)$ \\
\hline \multirow{9}{*}{ Shigatse } & 1 & 579.1 & $16,895.6$ & 32.3 \\
\hline & 2 & 449.3 & $10,331.4$ & 32.7 \\
\hline & 3 & 433.9 & $4,739.7$ & 24.8 \\
\hline & 4 & 323.7 & $5,079.7$ & 9.7 \\
\hline & 5 & 115.6 & $3,023.4$ & 18.3 \\
\hline & 6 & 205.2 & $4,854.4$ & 27.1 \\
\hline & 7 & 300.5 & $10,123.2$ & 18.0 \\
\hline & 8 & 746.7 & $45,327.2$ & 9.6 \\
\hline & 9 & 203.2 & $8,049.4$ & 24.7 \\
\hline \multirow{9}{*}{$\begin{array}{l}\text { Za'gya } \\
\text { Zangbo }\end{array}$} & 1 & 667.4 & $20,468.7$ & 80.1 \\
\hline & 2 & 595.8 & $16,187.2$ & 82.6 \\
\hline & 3 & 202.8 & $5,577.4$ & 104.5 \\
\hline & 4 & 357.1 & $9,348.8$ & 86.0 \\
\hline & 5 & 51.3 & 338.9 & 86.0 \\
\hline & 6 & 571.5 & $43,613.5$ & 112.0 \\
\hline & 7 & 522.0 & $73,292.1$ & 117.2 \\
\hline & 8 & 94.8 & $8,391.7$ & 112.6 \\
\hline & 9 & 283.0 & $*$ & $*$ \\
\hline Da Qaidam & 1 & 638.6 & $59,805.1$ & 118.1 \\
\hline
\end{tabular}

Notes: *, boundary is not defined because remote sensing image is not clear and the data are omitted. the river samples were collected upwind of Dune 1, the hilltop samples were collected on the hilltop in font of Dune 1, and the gobi samples were collected downwind of Dune 1. The fence samples were collected in the desert area downwind of Dune 1, from along the fence line that protects the railway.

The statistical results show that grain size characteristics vary greatly for different sand sources and reflect sand formation progress and environmental characteristics (Fig. 10). Finer, better-sorted grains reflect the influence of intensive winnowing processes downwind of obstacles. The rise of terrain from the river to the hilltop means that the grain size distribution reflects good winnowing processes. The sand shadow dune, gobi and fence samples represent deposition processes. From Table 2, it can be seen that the mean grain size of Dune 1 is smaller than those of the crescent dunes in the southeastern Tengger Desert

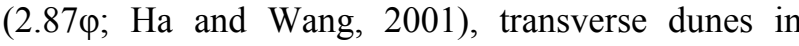
southern Mu Us Desert (2.23-2.94 $\varphi$; Ha et al., 2006) and pyramid dunes in the Taklimakan Desert $(2.43 \varphi$; Shi and Wang, 1986).

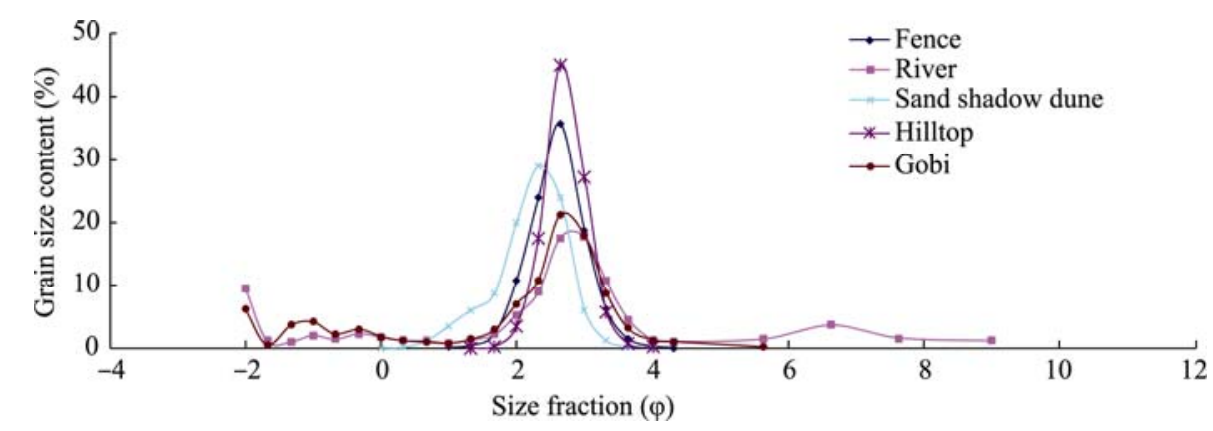

Fig. 10 Grain size content change at different locations near Dune 2 in Za'gya Zangbo

Table 2 Grain size content and parameters of grain sizes over Dune 1 in Za'gya Zangbo

\begin{tabular}{|c|c|c|c|c|c|c|c|c|c|c|c|c|}
\hline \multirow{2}{*}{$\begin{array}{l}\text { Sample } \\
\text { Site }\end{array}$} & \multicolumn{8}{|c|}{ Grain size content (\%) } & \multicolumn{4}{|c|}{ Grain size parameters $(\varphi)$} \\
\hline & $>2.00$ & $2.00-1.00$ & $1.00-0.50$ & $0.50-0.25$ & $\begin{array}{l}0.25-0.10 \\
(\mathrm{~mm})\end{array}$ & $0.10-0.05$ & $0.05-0.005$ & $0.005-0.001$ & $\mathrm{M}_{\mathrm{Z}}$ & $\sigma_{1}$ & $\mathrm{~S}_{1}$ & $\mathrm{~K}_{\mathrm{G}}$ \\
\hline River & 13.57 & 5.34 & 3.06 & 8.70 & 54.67 & 6.87 & 6.63 & 1.17 & 1.76 & 2.44 & -0.44 & 2.93 \\
\hline Hilltop & 0.00 & 0.00 & 0.00 & 3.69 & 95.50 & 0.80 & 0.00 & 0.00 & 2.54 & 0.30 & 0.07 & 1.08 \\
\hline Dune 1 & 0.00 & 0.07 & 4.77 & 34.63 & 60.20 & 0.34 & 0.00 & 0.00 & 2.06 & 0.49 & -0.24 & 1.14 \\
\hline Gobi & 14.46 & 7.03 & 2.87 & 11.31 & 58.73 & 5.40 & 0.20 & 0.00 & 1.52 & 2.05 & -0.71 & 1.89 \\
\hline Fence & 0.00 & 0.00 & 0.10 & 13.43 & 84.60 & 1.87 & 0.00 & 0.00 & 2.43 & 0.39 & 0.00 & 1.11 \\
\hline
\end{tabular}

Note: $\mathrm{M}_{\mathrm{Z}}$ denotes arithmetic mean diameters, $\sigma_{1}$ Standard Deviation, $\mathrm{S}_{1}$ Skewness, and $\mathrm{K}_{\mathrm{G}}$ Kurtosis. 


\subsection{Wind regime}

A wind rose depicts the frequency of wind occurrence from each of the specified wind direction sectors and the wind speed classes for a given location and time period. Figure 11 shows the wind roses at the three sites. Sand transport generally occurs at wind speeds greater than about $6 \mathrm{~m} / \mathrm{s}$ on the Qinghai-Tibet Plateau (Yin et al., 2013); thus, all wind speeds less than $6 \mathrm{~m} / \mathrm{s}$ were incorporated as a single class. The wind speeds shown are classified based on the Beaufort wind scale.
Data indicate that the prevailing winds at Shigatse are from the west $(15.5 \%$ of the time) and west-southwest (12.0\% of the time). The Amdo meteorological station near Za'gya Zangbo experiences the same general conditions as at Shigatse, with winds mostly from the west-northwest $(22.0 \%)$ and west (20.5\%). The Da Qaidam wind zone is much different: the prevailing winds are from the west-northwest (26.6\%) and northwest $(25.4 \%)$. We found that wind speeds are generally less than $6 \mathrm{~m} / \mathrm{s}$ at Shigatse and 6-12 m/s at Amdo and Da Qaidam (Fig. 11).


Fig. 11 Wind roses of daily maximum wind speed at the three sites: Shigatse (1976-2011), Amdo (1973-2011) and Da Qaidam (1982-2011)

The annual mean maximum wind speeds at Shigatse, Amdo and Da Qaidam are 5.5, 10.7 and $6.3 \mathrm{~m} / \mathrm{s}$, respectively (Fig. 12). The mean annual number of sand-driving wind days at Shigatse, Amdo and Da Qaidam are 148.0, 331.7 and 191.3 days, respectively.

The distributions of monthly mean maximum wind speed are similar at Shigatse and Da Qaidam. At Shigatse, the highest monthly mean wind speeds occur in March, followed by April and May, while at Da Qaidam, the maximum wind speeds occur in April, followed by May and March (Fig. 13). In contrast, the maximum wind speeds at Amdo occur in January, followed by February and April. The monthly mean wind speeds at Shigatse and Da Qaidam are lowest in November, whereas at Amdo, the lowest wind speeds occur in September. Wind speeds are related to topography. Amdo, in the plateau interior, is of higher altitude $(4,850 \mathrm{~m}$ asl) than the other locations and is affected by the Tanggula
Mountains, whereas Shigatse and Da Qaidam are of lower altitude $(4,000$ and 3,300 $\mathrm{m}$ asl, respectively) and are located on the edge of the Qinghai-Tibet Plateau.

\subsection{Sand transport}

Sand transport amount is one of the important indices which reflects sand transport intensity and direction in a region. Figure 14 shows the map of the amount of sand transport observed from October 2012 to September 2013. The dominant directions of sand laden wind is west all year. From August to March of the following year, the dominant direction is west, while the other months have variable wind directions. The amount of sand transport is greatest in February, November, January and December successively, while the smallest transport amount is in September and October.

\subsection{Wind tunnel experiments}

Three experimental wind tunnel setups were used, 
involving one, three and four models, respectively. Figure 15 shows the four-model setup in the wind tun- nel with $6-\mathrm{cm}$ gap spacing. Wind velocities of $6-8 \mathrm{~m} / \mathrm{s}$ formed small piles of sand downwind of the gap
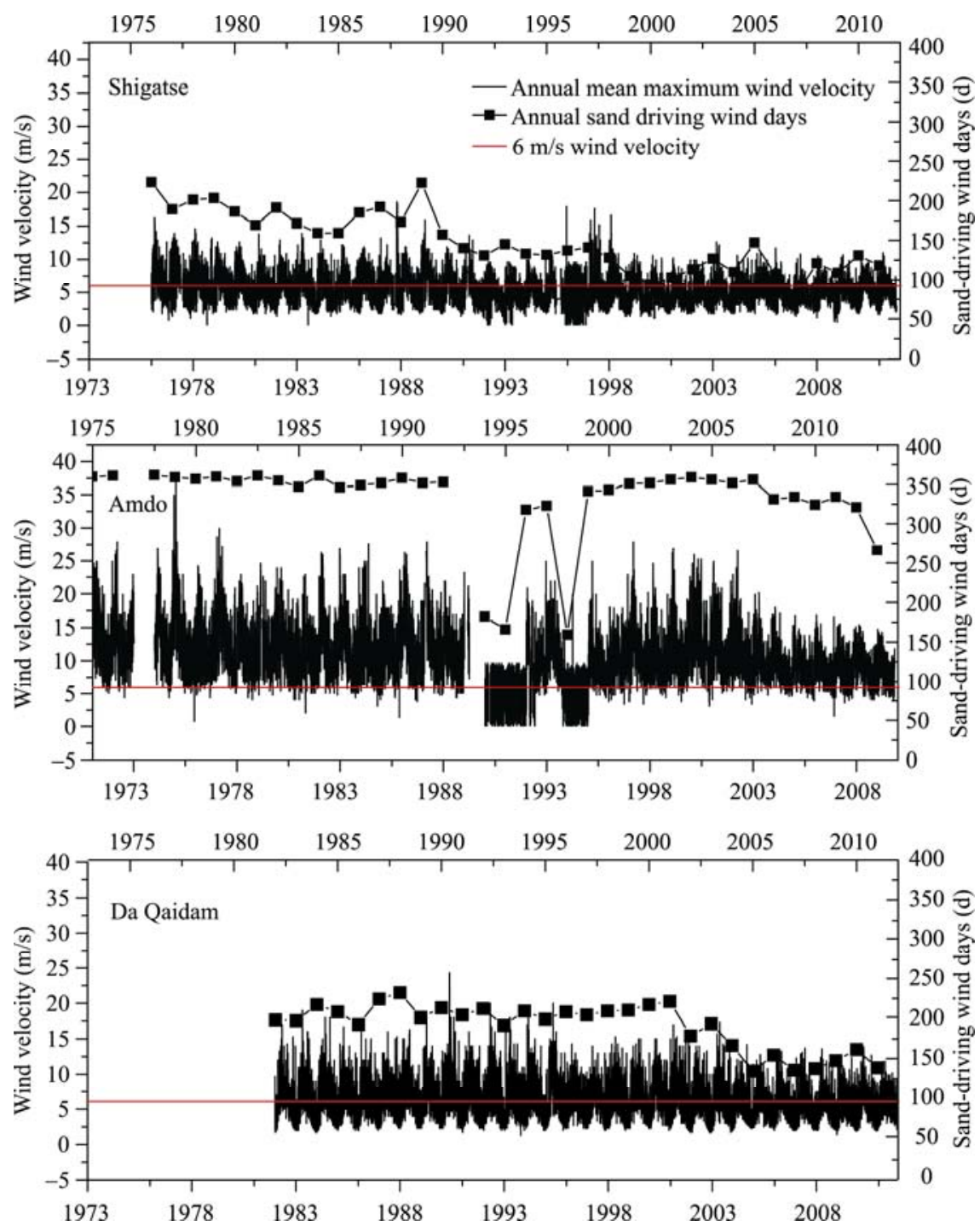

Fig. 12 Annual mean maximum wind speed and annual sand-driving wind days: Shigatse (1976-2011), Amdo (1973-2011) and Da Qaidam (1982-2011)

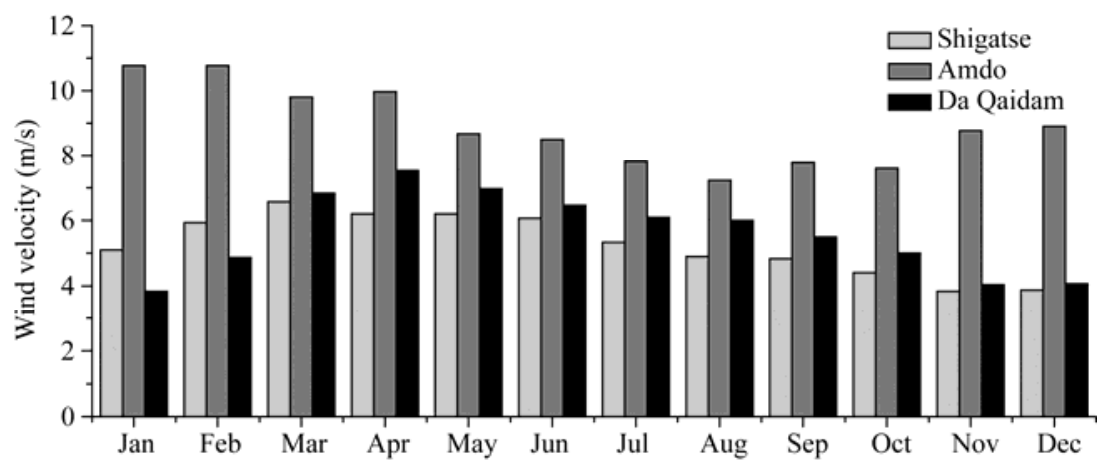

Fig. 13 Monthly mean maximum wind speed in the study areas 

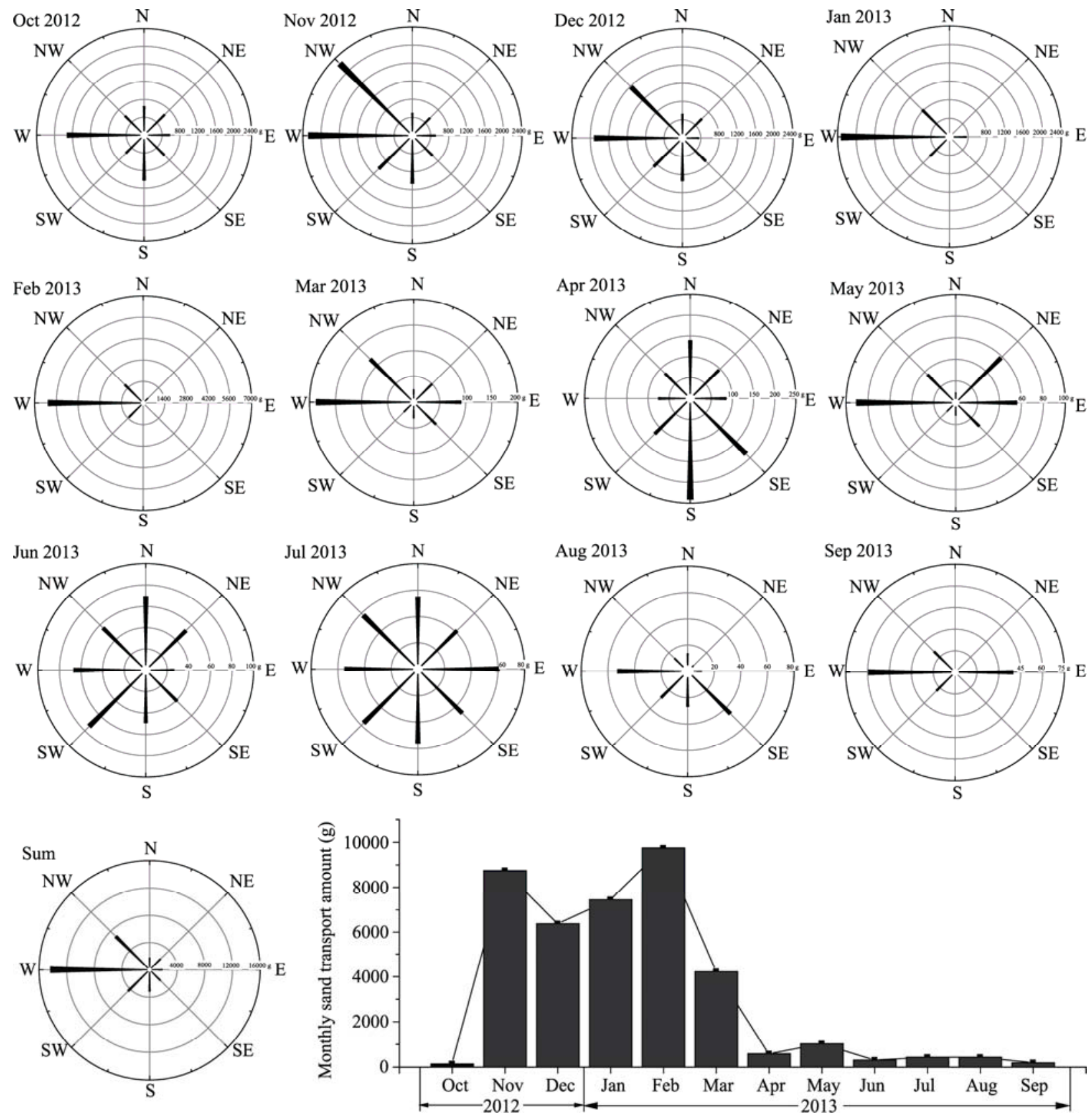

Fig. 14 Rose diagrams of sand transport amount in Za'gya Zangbo (October 2012-September 2013)

between the models (Figs. 15a-d). With a wind velocity of $10-15 \mathrm{~m} / \mathrm{s}$, the sand body became larger with lengths reaching $110 \mathrm{~cm}$ (Figs. 15e and $\mathrm{f}$ ). A wind velocity of $20 \mathrm{~m} / \mathrm{s}$ blew the sand body away from the gap and it became divided into two parts. These two parts were blown into the wind shadow areas behind the models (Figs. 15g-i). The experiment was repeated and on each occasion, we observed the same phenomenon (Figs. 15j and k). When the wind velocity is increased to $25 \mathrm{~m} / \mathrm{s}$, the sand bodies are blown away, leaving only a small residual amount of sand behind the model (Figs. 151-o). When only one model is set in the wind tunnel, a continuous distribution of the sand body forms around the model, but a distinct sand body behind the model does not develop. When three models are set with a gap spacing of $16 \mathrm{~cm}$, large sand bodies form downwind of the gap, but not behind the model. 


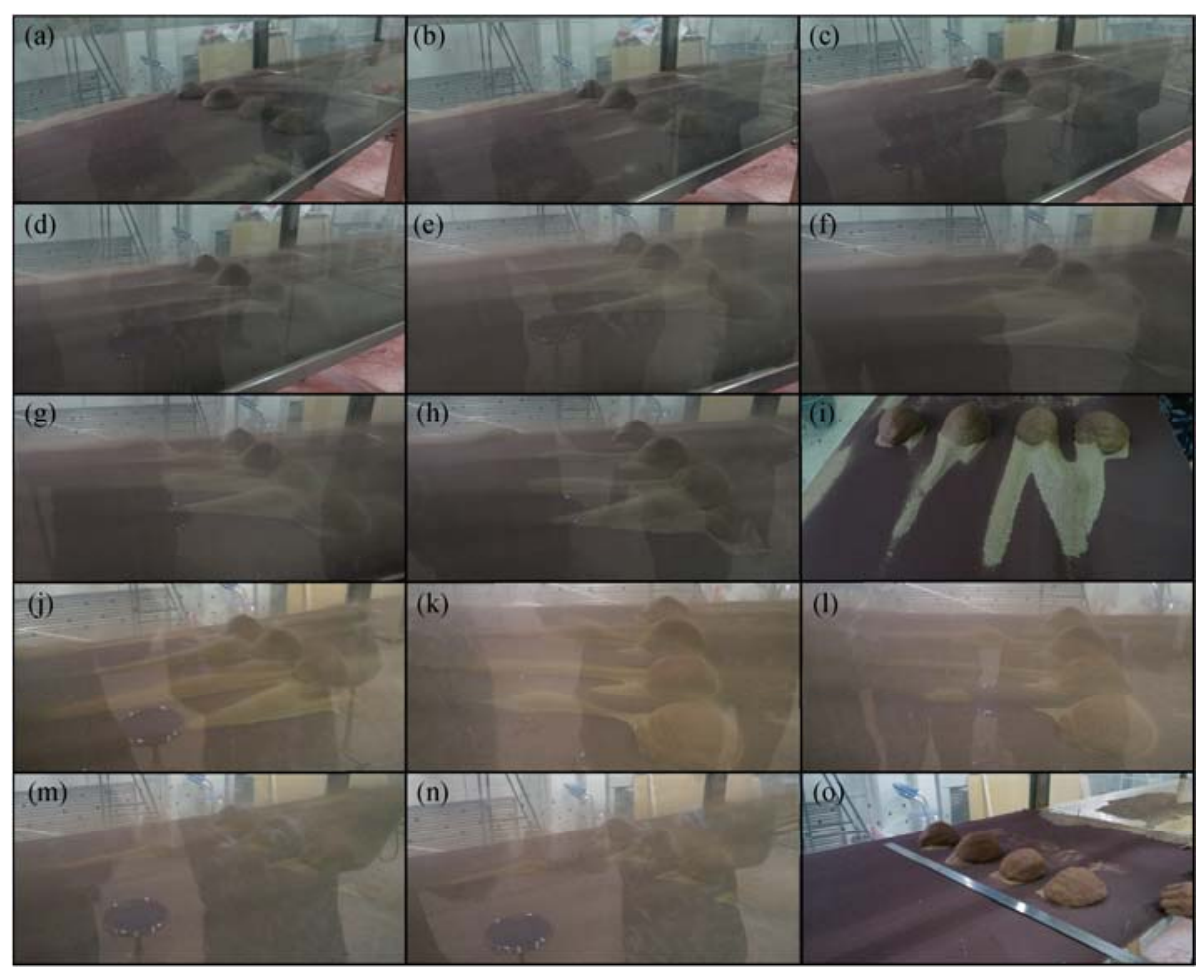

Fig. 15 Formation processes of sand shadow dunes in the wind tunnel experiments

\section{Discussion}

\subsection{Morphology of sand shadow dunes}

From the landform and morphology of Shigatse sand shadow dunes, we found that they are located in a broad valley on open ground. The wind flows through the valley, accelerating and blowing from west to east across a large area of cultivated farmland and three sides of the mountain diluvium. Wind-borne material from the sand dune area blows to the area of sand shadow dunes, which is located downwind of the wind zone. As shown in Fig. 4b, numerous hills are distributed within the area of the sand shadow dunes. When the wind carrying the sand material encounters obstacles (hills), it decelerates and flows around them, and the sand material accumulates. In the area upwind of the obstacle, this large accumulation of sand material is then transported downwind and flows through the complex obstacle. As the wind decelerates and flows around the obstacle, the sand material accumulates downwind of the hills and forms the sand shadow dunes. Sand shadow dunes are distributed downwind of the highest point of a hill. The wind blows across the hill and flows around it, merging downwind; the wind uplift is strongest at the highest point of the obstacle and weakest behind it. The morphology tells us that they have clear linear dune ridgeline, and end in the formation of crescent dunes.

As shown in Fig. 5, large amounts of sediment and alluvial material accumulate in the valley. The sides of the valley are flanked by two parallel mountains. The valley is naturally flat and allows significant wind to blow downstream from the river, eventually passing through a narrow gully and carrying river sand and diluvium from the mountain barrier it encounters. The airflow through these passes is strong and it transports large amounts of sand material. The leeward airflow from the mountain forms a shadow area, which contributes to the large accumulation of sandy material that forms the sand shadow dune. Figure 16 shows a contour map of the Za'gya Zangbo sand shadow dunes, and the position of the nine sand shadow dunes located in the lee of the mountain are indicated.

As shown in Fig. 6, the Da Qaidam sand shadow dune is located behind a small hill, and to the south forms a hill pass between the small hill and the large hill. The prevailing wind is westerly, and the sand 


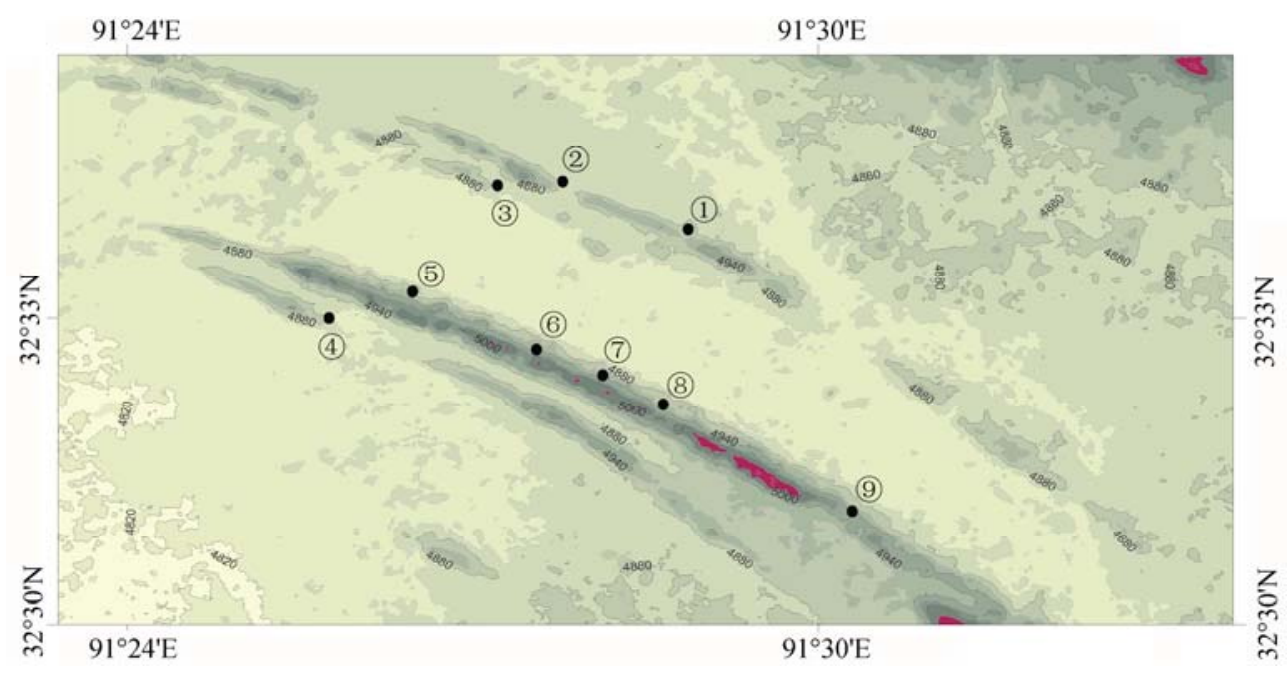

Fig. 16 Contour map of the Za'gya Zangbo sand shadow dunes (number 1-9 indicate the positions of the nine sand shadow dunes, respectively)

source is from the Qaidam Desert in the west. Wind-blown sand, most of which originates from the pass, encounters the hill, flows around it, and accumulates on the leeward side, forming the sand shadow dunes.

The morphological characteristics of the Da Qaidam and Za'gya Zangbo sand shadow dunes are similar. Both dune groups have a triangular distribution and an obvious sand ridgeline, with numerous crescent dunes in the downwind direction.

\subsection{Formation mechanism of sand shadow dunes}

Bagnold (1941) explained the mechanism for the formation of sand shadow dunes. The air, both in front of and behind the obstacle, is divided into two parts. The airflow is smooth away from the obstacle, but the volume of air within the obstacle's wind shadow is filled with swirls and vortices, which reduce average forward velocity. Further downwind of the obstacle, the forward velocity of the air inside the shadow zone gradually increases and the effects of the shadow fade.

In our study, we found that either one or both sides of the obstacle forming the sand shadow dune have a hill pass, which allows the transport of sand by wind. The wind upwind of the obstacle travels from a broader spacing to the narrower pass, such that the wind speed increases dramatically, in what is called a "narrow-pipe effect"; this allows the wind to flow around the obstacle quickly and for the sand material to flow through the pass. As shown by the shading in
Fig.17, a shadow zone forms downwind of the obstacle, in which the air is filled with swirls ad vortices, and where the wind speed is relatively lower. The sand flows through the pass and behind the obstacle, and some flows into the shadow zone. Because the wind speed in the shadow zone is relatively lower, sand settles and accumulates here. In addition, the disturbed air in the shadow allows the deposited material to accumulate gradually in the middle. Further downwind off the obstacle, the forward velocity of the air inside the shadow zone gradually increases, and the shadow area decreases gradually until the shadowing effect of the obstacle eventually disappears. Depending on the obstacle, as sand accumulates in the shadow zone, sand unaffected by the shadow zone will be carried away, leaving the gradually formed sand shadow dunes unchanged. The morphological characteristics of the sand shadow dunes are related to the morphological characteristics of the obstacle, shape of the pass and wind regime.

\subsection{Relationship between these sand shadow dun- es and other dunes}

Basing on landform characteristics, wind regime and sand transport, we found that the type of sand shadow dune discovered on the Qinghai-Tibet Plateau is influenced by many environmental factors specific to the area: strong wind, abundant sand sources, distinctive topography and dry climate. The high elevations and complex topography create distinctive atmospheric 

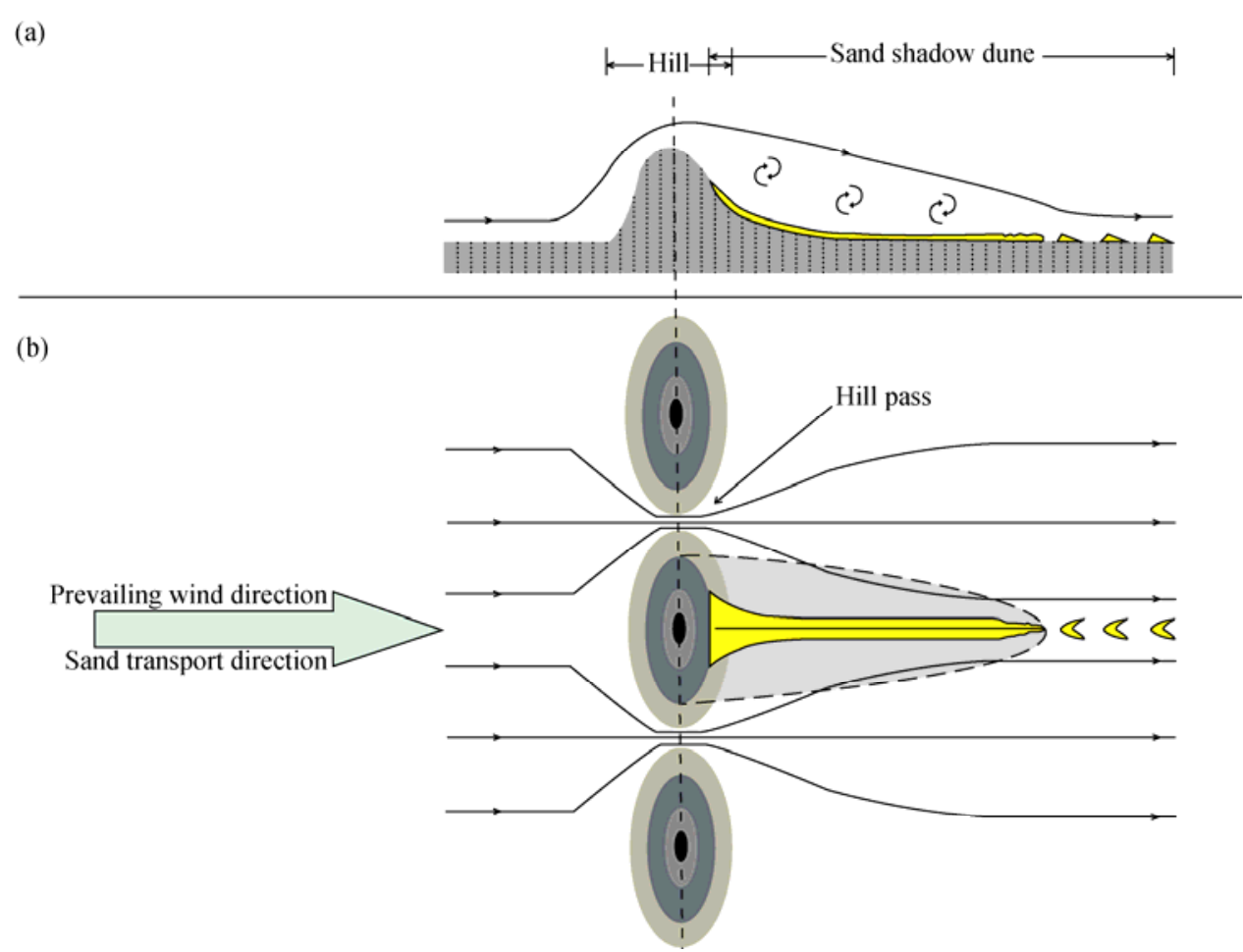

Fig. 17 Formation mechanism of sand shadow dunes ((a) is side view and (b) is top view)

circulation patterns, causing high wind speeds, dry, cold air, sparse vegetation and lower air densities and pressures (Beniston et al., 1997). The frequent geological tectonic movements in the Qinghai-Tibet Plateau have formed many mountains and complex landforms, and intensive erosion from water, wind and freeze-thaw cycles has increased the amount of sediment and fragmented alluvial material, which are the principal sources of sand for dunes. The specialized environment of the Qinghai-Tibet Plateau is favorable for the formation of sand shadow dunes.

The morphological characteristics and formation mechanisms of the sand shadow dunes studied in this paper indicate that they are mature sand shadow dunes. They form under harsh conditions, with a hill pass on either one or both sides of the obstacle, and they are linear sand dunes with significant ridges and crescent dunes downwind. The wind tunnel experiments showed that the gap is important for the formation of sand shadow dunes. The gap spacing and wind velocity are all important factors.

Typical sand shadow dunes, found downwind of obstacles, such as sand interspersed with small amounts of accumulated material, have no clear linear dune ridgelines, and do not end in the formation of crescent dunes (Bagnold, 1941). The dunes in this study are mature sand shadow dunes, which not only have the characteristics of typical sand shadow dunes, but also have linear sand shadow dunes (longitudinal dunes). This type of sand shadow dune, newly discovered on the Qinghai-Tibet Plateau, reflects the special environmental factors in Tibet, including intense wind, abundant sand material sources, distinctive geological structures and topography.

The sand shadow dunes in this study are different from the sand drifts between obstacles first studied by Bagnold (1941). Although sand drifts have both an obstacle and a gap, they form downwind of the gap, whereas sand shadow dunes form downwind of the obstacles. Furthermore, their formation mechanisms are different.

The Qinghai-Tibet Plateau also has large climbing dunes (Li et al., 1997; Liu et al., 1999), but their morphological characteristics and formation mechanisms are different from those of sand shadow dunes. Climbing dunes form on the windward slopes of obstacles, whereas sand shadow dunes form in their lees. Another difference is that climbing dunes are distrib- 
uted in areas where the air does not flow through a pass. Climbing dunes are formed when wind and large amounts of sand material encounter obstacles, such as mountains, and air accelerates over the obstacle. When the sandy material is unable to pass over the obstacles, it deposits on the windward side, and it then accumulates to form a climbing dune. However, sand shadow dunes are formed when the airflow carrying the sand material passes around the obstacles and the sand material deposits to form a dune on the leeward side.

Sand shadow dunes are also different from linear dunes (longitudinal dunes). Linear dunes are relatively large (more than $600 \mathrm{~m}$ long) compared with sand shadow dunes. Furthermore, linear dunes do not need obstacles and a pass, which are prerequisite formation conditions for sand shadow dunes (Jackson and Hunt, 1975; Wiggs, 2001).

Barchans (crescent-shaped dunes) are one of the most common dunes in nature and have been studied by many researchers (Lancaster et al., 1996; Elbelrhiti et al., 2008). The sand shadow dunes in this study are morphologically similar to barchan chains, such as Dune 1 in the Za'gya Zangbo sand shadow dune group. This dune has hook-shaped dunes at its end that appear similar to barchan chains; it exists as an individual dune because of the special wind regime and topography.

\section{Conclusions}

In this paper, two areas of sand shadow dunes in Shigatse and Za'gya Zangbo of Tibet and a separate sand shadow dune in Da Qaidam of Qinghai, were studied to compare their topographies and morphologies, and the physical characteristics of the sand, wind regime and other features with those of typical sand shadow dunes, climbing dunes and linear dunes. A sand shadow is the sheltered area behind the leeward side of an obstacle in which sediment accumulates. The sand shadow dunes in our study are different from those first described by Bagnold (1941). The sand shadow dunes in our study formed when wind transporting sand material accelerated around one or both sides of the obstruction and through a hill pass. The distinctive morphological characteristics of our sand shadow dunes include an obvious linear dune ridgeline at the end of the body and the form of crescent dunes.

According to the wind tunnel experiment, the gap is important for the formation of sand shadow dunes. The gap spacing and the wind velocity are critical factors. Only when gap spacing is $2 / 3(6 \mathrm{~cm} / 9 \mathrm{~cm}$ in our model experiments) the hill height, it is most suitable for their formation. When wind velocity is $20 \mathrm{~m} / \mathrm{s}$, the sand body will be divided into two parts, which form the sand shadow dunes behind the hill body.

We observed that the following conditions are necessary for sand shadow dunes to form: (1) strong winds, sufficient sand, suitable obstacles and a dry climate; (2) one or both sides of the obstacle forming the shadow zone has a hill pass, which allows the passage of wind and sand; and (3) the windward side of the obstacle has a wide, flat area, which provides adequate spacing for the wind flow and transport of sand material, and the leeward side also has a sufficiently broad, flat area to allow the release of the wind and transported sand.

The research on this new type of sand shadow dune could greatly contribute to the understanding of dune geomorphology. In future research, wind tunnel and numerical simulations will be performed, which should include height, windward and leeward slope of the obstacle, flow direction and the pass between the obstacles. Quantitative studies of these factors could lead to a better understanding of their formation mechanism and verify our conclusions.

\section{Acknowledgements}

This work was supported by the National Natural Science Foundation of China (40930741) and National Basic Research Program of China (2012CB026105). The authors gratefully acknowledge the anonymous reviewers and the editor whose comments and suggestions were helpful in improving the quality of this paper.

\section{References}

Bagnold R A. 1941. The Physics of Blown Sand and Desert Dunes. London: Methuen, 188-196.

Beniston M, Diaz H F, Bradley R S. 1997. Climatic change at high elevation sites: an overview. Climatic Change, 36(3-4): 233-251. 
Bressolier C, Thomas Y F. 1977. Studies on wind and plant interactions on French Atlantic coastal dunes. Journal of Sedimentary Research, 47(1): 331-338.

Cooke R U, Warren A. 1973. Geomorphology in Deserts. London: B T Batsford, 255-258.

Cooper W S. 1958. Coastal Sand Dunes of Oregon and Washington. New York: Geological Society of America, 168-172.

Elbelrhiti H, Claudin P, Andreotti B. 2005. Field evidence for surface-wave-induced instability of sand dunes. Nature, 437(29): $720-723$.

Elbelrhiti H, Andreotti B, Claudin P. 2008. Barchan dune corridors: field characterization and investigation of control parameters. Journal of Geophysical Research: Earth Surface, 113(F2): F02S15.

Elbelrhiti H. 2012. Initiation and early development of barchans dunes: a case study of the Moroccan Atlantic Sahara desert. Geomorphology, 138(1): 181-188.

Evans J R. 1962. Falling and climbing sand dunes in the Cronese ("Cat") mountains, San Bernardino County, California. The Journal of Geology, 70(1): 107-113.

Gunatilaka A, Mwango S B. 1989. Flow separation and the internal structure of shadow dunes. Sedimentary Geology, 61(1-2): 125-134.

Ha S, Wang G Y. 2001. Characteristics of grain size over crescentic dunes in Shapotou, southeastern Tengger Desert. Journal of Desert Research, 21(3): 271-275. (in Chinese)

Ha S, Zhuang Y M, Wang L, et al. 2006. Grain-size variation on a transverse dune and response to wind direction changes on southern edge of Mu Us Desert. Progress in Geography, 25(6): 42-51. (in Chinese)

Hesp P A. 1981. The formation of shadow dunes. Journal of Sedimentary Research, 51(1): 101-112.

Jackson P S, Hunt J C R. 1975. Turbulent wind flow over a low hill. Quarterly Journal of the Royal Meteorological Society, 101(430): 929-955.

Lancaster N. 1995. Geomorphology of Desert Dunes. London: Routledge, 115-119.

Lancaster N, Nickling W G, Neuman C K M, et al. 1996. Sediment flux and airflow on the stoss slope of a barchan dune. Geomorphology, 17(1-3): 55-62.

Li S, Wang Y, Ha S, et al. 1997. Classification and development of aeolian sand landform in the Yurlung Zangbo valley. Journal of Desert Research, 17(4): 342-350. (in Chinese)

Li Z S, Ni J R. 2000. A review of desert dune geomorphology. Journal of Sediment Research. 5: 73-81. (in Chinese)

Liu X W, Li S, Shen J Y. 1999. Wind tunnel simulation experiment of mountain dunes. Journal of Arid Environments, 42(1): 49-59.

Livingstone I, Wiggs G F S, Weaver C M. 2007. Geomorphology of desert sand dunes: a review of recent progress. Earth-Science Reviews, 80: 239-257.

Luo W Y, Dong Z B, Qian G Q, et al. 2012a. A research review on aerodynamic effects of shelter fences. Journal of Desert Research. 32(4): 885-895. (in Chinese)

Luo W Y, Dong Z B, Qian G Q, et al. 2012b. Wind tunnel simulation of the three-dimensional airflow patterns behind cuboid obstacles at different angles of wind incidence, and their significance for the formation of sand shadows. Geomorphology, 139-140: 258-270.

Luo W Y, Dong Z B, Qian G Q, et al. 2014. Near-wake flow patterns in the lee of adjacent obstacles and their implications for the formation of sand drifts: a wind tunnel simulation of the effects of gap spacing. Geomorphology, 213: 190-200.

Pidgeon I M. 1940. The ecology of the central coastal area of New South Wales. III. Types of primary succession. Proceedings of the Linnean Society of New South Wales, 65: 221-249.

Pye K, Tsoar H. 1990. Aeolian Sand and Sand Dunes. London: Unwin Hyman, 89-93.

Salisbury E. 1952. Downs and Dunes: Their Plant Life and Its Environment. London: G. Bell and Sons Ltd, 168-177.

Shi P J, Wang J A. 1986. Aeolian sand grain size of statistical analysis in arid and semiarid area of China. Journal of Inner Mongolia Normal University: Natural Science Edition, 4: 12-21. (in Chinese)

Tang J N, Su Z Z, Ding F, et al. 2011. The formation age and evolution of Kumtagh Desert. Journal of Arid Land, 3(2): 114-122.

Tsoar H. 1983. Wind tunnel modeling of echo and climbing dunes. Amsterdam: Elsevier, 247-259.

Tsoar H, Blumberg D G. 2002. Formation of parabolic dunes from barchan and transverse dunes along Israel's Mediterranean coast. Earth Surface Processes and Landforms, 27(11): 1147-1161.

Wang X M, Dong Z B, Zhang J W, et al. 2004. Formation of the complex linear dunes in the central Taklimakan Sand Sea, China. Earth Surface Processes and Landforms, 29(6): 677-686.

Wiggs G F S. 2001. Desert dune processes and dynamics. Progress in Physical Geography, 25(1): 53-79.

Wu Z. 2003. Aeolian Landform and Sand Control Engineering. Beijing: Science Press, 261-266. (in Chinese)

Yin D Y, Qu J J, Han Q J, et al. 2013. Wind-blown sand activity intensity in Cuonahu Lake section of Qinghai-Tibet Railway. Journal of Desert Research, 33(1): 9-15. (in Chinese)

Zhao Y J. 1991. The influence of Mazhatag Mountain on wind sandy landforms in its two sides. Arid Zone Research, 8(1): 8-12. (in Chinese)

Zhu Z D, Chen Z P, Wu Z, et al. 1981. Study on the Aeolian Geomorphology of the Taklimakan Desert. Beijing: Science Press, 110-112. (in Chinese) 